\title{
The efficacy of a supervised and a home-based core strengthening programme in adults with poor core stability: a three-arm randomised controlled trial
}

\author{
V H Chuter, ${ }^{1,2}$ X A K Janse de Jonge, ${ }^{2,3}$ B M Thompson, ${ }^{3}$ R Callister ${ }^{2,4}$
}

\begin{abstract}
- Additional material is published online only. To view please visit the journal online (http://dx.doi.org/10.1136/ bjsports-2013-093262).

${ }^{1}$ School of Health Sciences, The University of Newcastle, Australia

${ }^{2}$ Priority Research Centre for Physical Activity and Nutrition, The University of Newcastle, Australia

${ }^{3}$ School of Environmental and Life Sciences, The University of Newcastle, Australia

${ }^{4}$ School of Biomedical Sciences and Pharmacy, The University of Newcastle, Australia
\end{abstract}

\section{Correspondence to} $\mathrm{V} H$ Chuter, School of Health Sciences, The University of Newcastle, Ourimbah NSW 2258, Australia;

Vivienne.Chuter@newcastle. edu.au

Accepted 13 October 2014 Published Online First 10 November 2014

\section{ABSTRACT \\ Background Poor core stability is linked to a range of musculoskeletal pathologies and core-strengthening programmes are widely used as treatment. Treatment outcomes, however, are highly variable, which may be related to the method of delivery of core strengthening programmes. We investigated the effect of identical 8 week core strengthening programmes delivered as either supervised or home-based on measures of core stability.}

Methods Participants with poor core stability were randomised into three groups: supervised $(n=26)$, homebased $(n=26)$ or control $(n=26)$. Primary outcomes were the Sahrmann test and the Star Excursion Balance Test (SEBT) for dynamic core stability and three endurance tests (side-bridge, flexor and Sorensen) for static core stability. The exercise programme was devised and supervised by an exercise physiologist.

Results Analysis of covariance on the change from baseline over the 8 weeks showed that the supervised group performed significantly better on all core stability measures than both the home-based and control group. The home-based group produced significant improvements compared to the control group in all static core stability tests, but not in most of the dynamic core stability tests (Sahrmann test and two out of three directions of the SEBT).

Conclusions Our results support the use of a supervised core-strengthening programme over a homebased programme to maximise improvements in core stability, especially in its dynamic aspects. Based on our findings in healthy individuals with low core stability, further research is recommended on potential therapeutic benefits of supervised core-strengthening programmes for pathologies associated with low core stability. Trial registration number ACTRN12613000233729.

\section{INTRODUCTION}

Core stability refers to the ability of core musculature to stabilise the spine. ${ }^{1}$ It is required to increase stiffness of the trunk and hip in preparation for, and in response to, spinal loading, to prevent instability of the vertebral column and to facilitate return to equilibrium following perturbation. ${ }^{2}$ Poor core stability is linked to development of a range of musculoskeletal pathologies of the spine and lower extremities, including low back pain ${ }^{3}$ and over-use injuries of the hip, knee, ankle and foot. ${ }^{4-6}$

Core strengthening programmes aim to improve core stability by developing strength, endurance and neuromuscular control of core muscles. ${ }^{7}$ Such programmes are currently recommended as a primary treatment for chronic low back pain. ${ }^{8}$
Despite widespread use, treatment outcomes are highly variable and the efficacy of this exercise approach for treatment of pathology remains unclear. $^{9} 10$

A possible source of the heterogeneity of therapeutic outcomes following core-strengthening programmes is the method of programme delivery, with both supervised and home-based programmes in common use. Home-based exercise programmes of any type offer several benefits over supervised programmes including greater flexibility for patients and reduced associated healthcare system costs. However, home-based programmes rely on the participants' motivation and ability to correctly perform the exercises independently, and selfreported compliance is similar to, or lower than, supervised programmes. ${ }^{11}$

To date there has been little investigation of the effect of home-based versus supervised exercise programmes for core stability. Bronfort et $a l^{12}$ found better results with a supervised core-strengthening programme. However, as different exercises were used for the home-based and supervised group, it was not possible to determine if this was due to the delivery method or the specific exercises used. Poorer outcomes for homebased core strengthening programmes may be related to the difficulty participants have effectively performing exercises without external feedback. Specific instructions, as are given under supervision, induced improved activation of deep core stabilising muscles during trunk flexion activities. ${ }^{13}$ It is unknown, however, to what extent the absence of such instruction affects the efficacy of a homebased programme. Thus, we determined the effect of identical core-strengthening programmes delivered as either a (1) supervised or (2) home-based programme compared to (3) no intervention on measures of core stability.

\section{METHODS}

This was a three-arm, stratified (gender, age) with balanced randomisation, single-blind, controlled, parallel-group study conducted on the University of Newcastle Central Coast Campus. This project was approved by the institutional Human Research Ethics Committee and was registered with the Australian and New Zealand Clinical Trials Registry (available at http://www.ANZCTR. org.au/ACTRN12613000233729.aspx). Participants were recruited on a volunteer basis from staff and students via flyer advertising.

Inclusion criteria were 18 years of age or over with a Sahrmann test score of level 1 or lower 
indicating poor core stability. Exclusion criteria included current pregnancy, current acute specific low back pain, current acute lower limb injury or any musculoskeletal, neurological, systemic or local pathology affecting balance, neuromuscular control or altering muscle response to exercise and current or previous participation in any form of core-strengthening programme.

\section{Randomisation}

Participants were randomised into the intervention or control groups with a software randomisation function by a researcher independent of the trial. Randomisations were stratified for age and gender.

\section{Interventions}

This trial used two interventions and a control. The first intervention was a supervised core-strengthening programme which was performed over 8 weeks, with participants required to attend two classes per week. ${ }^{1}{ }^{14-20}$ Details of the programme and rationale for included exercises are provided in online supplementary file 1 . This programme was conducted by an exercise physiologist not involved in recruitment or testing who provided instruction, demonstration and individual feedback on correct execution of exercises. Compliance at these sessions was monitored via an attendance record completed by the exercise physiologist.

The second intervention was a home-based core-strengthening programme. Participants in the home-based programme received an initial instructional class in which they were taught the principles of deep abdominal muscle activation and the progression of all exercises used in the programme. They were also provided with written and diagrammatic instructions to follow for two sessions per week for 8 weeks. All exercise sessions in the homebased programme were identical to those in the supervised programme. All instructional sessions were provided by the same exercise physiologist who ran the supervised group classes. Compliance was assessed using a self-reported compliance questionnaire.

The third group served as controls and participated in baseline and follow-up testing only. All groups were instructed not to change their physical activity levels outside the prescribed programmes.

\section{Procedures}

Potential participants were initially screened using the Sahrmann test. Participants achieving a score of level one or less were then eligible to enter the trial. The baseline testing consisted of the Sahrmann test to evaluate dynamic lumbopelvic stability, ${ }^{21} 22$ three tests of static trunk muscle endurance requiring sustained isometric contraction, (the side bridge endurance test, ${ }^{14}$ the flexor endurance test ${ }^{18}$ and the Sorensen test ${ }^{23}$ ) and the Star Excursion Balance Test (SEBT) ${ }^{24-26}$ to assess dynamic postural stability in three directions (anterior, posterolateral and posteromedial). ${ }^{27}$ Details of and rationale for these tests are provided in online supplementary file 2.

The participants were then randomised to one of the three groups. The trial began once 13 participants had been recruited for the supervised core-strengthening group to allow for adequate class size. Within 1 week of completion of the 8 week intervention all participants performed the same tests as at baseline. All assessments were performed by the same researcher, who was blinded to participant group allocation.

Test-retest reliability of all core stability tests was assessed on a separate group of 15 participants who met the main study inclusion criteria. Following baseline testing these participants returned 7-10 days later and repeated all core stability assessments. The testing was completed by the same researcher who performed baseline and follow-up testing.

A sample size of 26 per group was calculated based on a minimally important change of $7 \%$ for the SEBT assuming a SD of $10 \%$, a power of $90 \%$, an $\alpha$ of 0.05 and allowing for $10 \%$ attrition rate. ${ }^{28}$

\section{Outcomes}

Primary outcomes were change in dynamic lumbopelvic stability measured with the Sahrmann test, change in independent measures of static core stability assessed with the side bridge endurance test, the flexor endurance test and the Sorensen test and, change in dynamic postural stability measured with the SEBT. Secondary outcomes were compliance with the intervention and adverse events.

\section{Statistical analysis}

Statistical analysis was conducted on a blinded, intention-to-treat basis using SPSS software (V.21.0 SPSS Chicago, Illinois, USA). For the primary outcomes, data were analysed with analysis of covariance (ANCOVA) using a linear regression approach to investigate change from baseline following the 8 week intervention for each variable. The baseline measure was the only covariate used in each analysis. Cohen's d was used to calculate effect sizes. An effect size of greater than or equal to 0.8 was considered to represent a large clinical effect, 0.5 a moderate effect and 0.2 a small effect. ${ }^{29}$ Correlations were performed between all measures of core stability and self-reported and recorded compliance for the home-based and supervised group, respectively.

For the reliability component intraclass correlation coefficients (ICC) with 95\% CI were calculated to determine level of agreement between test and retest for all measurements. All ICC values for test-retest reliability were interpreted according to criteria recommended by Fleiss. ${ }^{30}$ Paired t tests were performed to determine whether statistically significant differences existed between sessions.

\section{RESULTS}

Seventy-eight participants were recruited between June and September 2012. Participant characteristics are included in table 1. Figure 1 demonstrates participants' progression through the trial. Participants in the supervised core strengthening programme attended approximately $76 \%(12.1)$ of the 16 scheduled classes for their programme. Those in the home-based programme self-reported a higher mean compliance rate with an average of $85 \%$ (13.6) of the 16 sessions completed. The trial

Table 1 Participant characteristics

\begin{tabular}{lllll}
\hline Group & $\begin{array}{l}\text { Sample } \\
\text { size }\end{array}$ & Gender & $\begin{array}{l}\text { Age } \\
\text { (years) }\end{array}$ & BMI $\left(\mathbf{k g} / \mathbf{m}^{2}\right)$ \\
\hline Supervised program & 26 & $\begin{array}{l}15 \text { males } \\
11 \text { females }\end{array}$ & $26.31(4.12)$ & $25.29(1.53)$ \\
Home-based program & 26 & $\begin{array}{l}14 \text { males } \\
12 \text { females }\end{array}$ & $25.22(3.51)$ & $23.24(1.98)$ \\
Control & 26 & $\begin{array}{l}15 \text { males } \\
11 \text { females }\end{array}$ & $27.01(3.90)$ & $26.12(2.01)$ \\
Reliability & 15 & $\begin{array}{l}10 \text { males } \\
5 \text { females }\end{array}$ & $24.68(3.62)$ & $24.25(2.55)$ \\
\hline
\end{tabular}

Data are counts or mean (SD). 


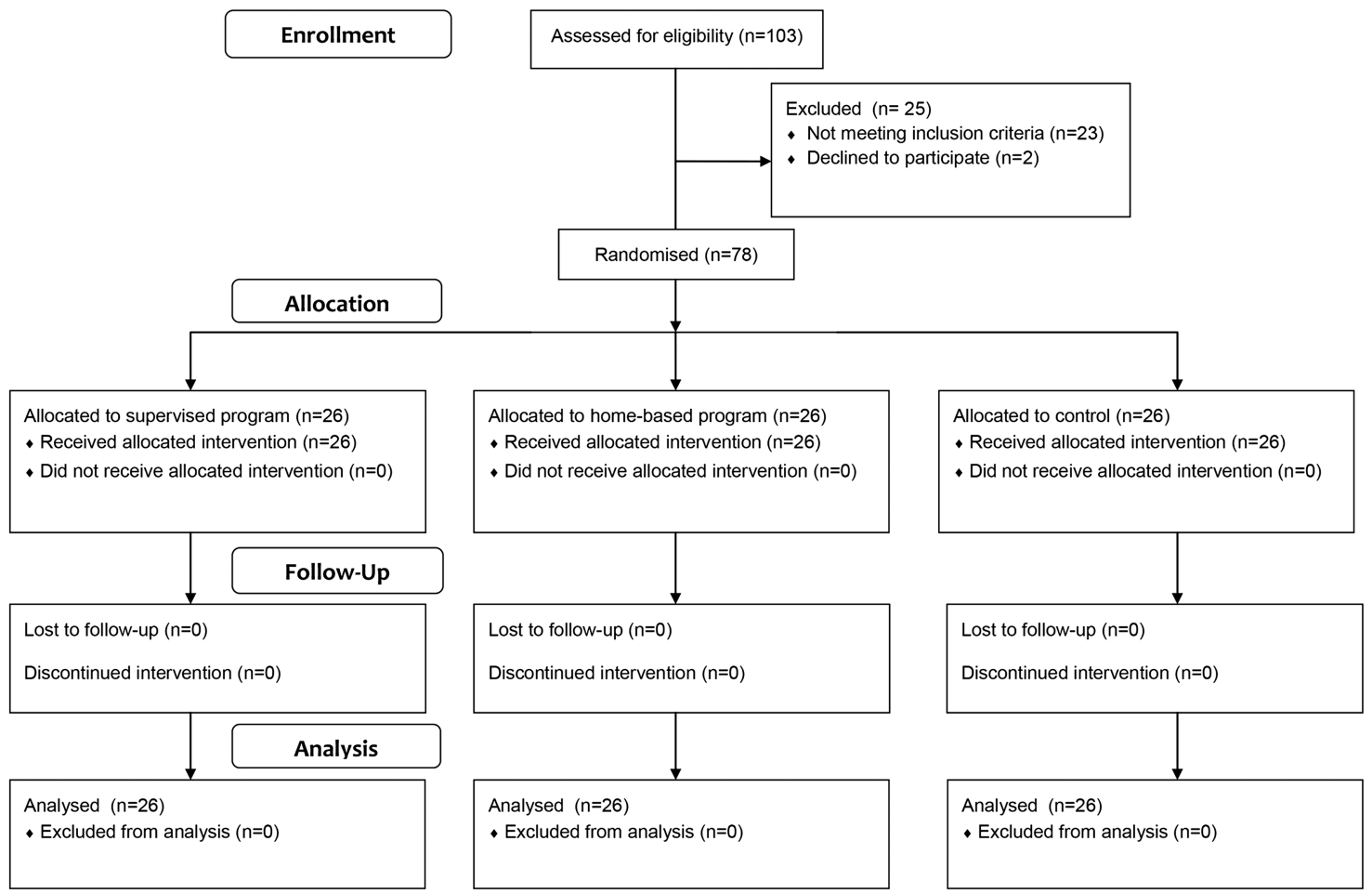

Figure 1 CONSORT flow diagram of participants' progression through the trial.

was ended once 26 participants had completed each intervention. The characteristics of the reliability group are also shown in table 1 .

\section{Measures of core stability}

Participants in the supervised core-strengthening programme demonstrated more statistically significant improvements in mean scores on all measures of core stability than those in the home-based programme and the control group and effect sizes were generally moderate to large (tables 2 and 3 ) and significant for the Sahrmann and Sorenson tests. The home-based programme produced significant improvements compared to the control group in most tests, except for the Sahrmann test and the SEBT posterolateral and posteromedial directions which had small to moderate effect sizes (tables 2 and 3).

\section{Correlations}

Correlations between compliance and outcomes of tests of core stability were strongest for the supervised group (table 4).
Significant positive correlations were demonstrated between the number of sessions attended in the supervised group and all core stability outcomes, except for the side bridge. In the home-based programme only outcomes for the flexor endurance test were positively correlated with self-reported compliance (table 4).

\section{Reliability}

Test-retest reliability for functional tests of core stability was excellent with ICCs ranging from 0.80 to 0.91 (table 5). Paired samples $t$ tests demonstrated no significant differences between test and retest measures.

\section{Adverse events}

There were no reported adverse events associated with this research.

\section{DISCUSSION}

We found that a supervised core-strengthening programme results in significantly greater improvements in static and

Table 2 Adjusted means for follow-up core stability testing

\begin{tabular}{|c|c|c|c|c|c|c|c|}
\hline & $\begin{array}{l}\text { Sahrmann } \\
\text { (level) }\end{array}$ & $\begin{array}{l}\text { Side-bridge } \\
\text { endurance (s) }\end{array}$ & $\begin{array}{l}\text { Flexor } \\
\text { endurance (s) }\end{array}$ & Sorensen (s) & $\begin{array}{l}\text { SEBT } \\
\text { Anterior }(\mathrm{cm})\end{array}$ & SEBT posterolateral $(\mathrm{cm})$ & SEBT posterolateral $(\mathrm{cm})$ \\
\hline \multicolumn{8}{|c|}{ Supervised group } \\
\hline Mean & 2.63 & 27.84 & 53.60 & 26.51 & 87.69 & 79.21 & 83.01 \\
\hline $95 \% \mathrm{Cl}$ & 2.09 to 2.92 & 23.38 to 31.11 & 47.12 to 60.23 & 21.74 to 31.29 & 84.08 to 91.22 & 75.68 to 82.61 & 78.79 to 87.34 \\
\hline \multicolumn{8}{|c|}{ Home-based group } \\
\hline Mean & 1.14 & 20.62 & 41.09 & 21.27 & 84.25 & 73.71 & 77.02 \\
\hline $95 \% \mathrm{Cl}$ & 0.66 to 1.41 & 16.83 to 23.49 & 33.52 to 45.65 & 16.49 to 26.13 & 80.31 to 87.80 & 70.19 to 76.10 & 72.82 to 82.26 \\
\hline \multicolumn{8}{|c|}{ Control group } \\
\hline Mean & 0.90 & 13.91 & 27.28 & 15.44 & 80.36 & 72.02 & 74.43 \\
\hline $95 \% \mathrm{Cl}$ & 0.51 to 1.14 & 10.59 to 17.30 & 20.68 to 33.91 & 10.63 to 20.17 & 76.88 to 84.01 & 68.64 to 75.02 & 70.08 to 78.06 \\
\hline
\end{tabular}


Table 3 Effect sizes (Cohen's d) in mean $(95 \% \mathrm{Cl})$ and $\mathrm{p}$ values for difference in adjusted means between groups at follow-up

\begin{tabular}{|c|c|c|c|c|c|c|}
\hline \multirow[b]{2}{*}{ Core stability test } & \multicolumn{2}{|l|}{ Supervised vs control } & \multicolumn{2}{|c|}{ Supervised vs home-based } & \multicolumn{2}{|c|}{ Home-based vs control } \\
\hline & Effect size & $\mathrm{p}$ Value & Effect size & $p$ Value & Effect size & p Value \\
\hline Sahrmann & 2.06 (1.86 to 2.26$)$ & 0.0001 & 1.45 (0.84 to 2.06$)$ & 0.0001 & $0.27(-0.27$ to 0.81$)$ & 0.09 \\
\hline Side-bridge endurance & $1.75(-0.42$ to 3.90$)$ & 0.0001 & $0.83(-1.53$ to 3.19$)$ & 0.0001 & $0.81(-1.43$ to 3.07$)$ & 0.001 \\
\hline Flexor endurance & $2.35(-0.70$ to 5.39$)$ & 0.0001 & $1.19(-1.66$ to 4.03$)$ & 0.0001 & $1.45(-1.12$ to 4.03$)$ & 0.01 \\
\hline Sorensen & 1.46 (0.61 to 3.53 ) & 0.001 & $0.67(-1.43$ to 2.78$)$ & 0.03 & 0.81 (-1.15 to 2.78$)$ & 0.02 \\
\hline SEBT anterior & $0.73(-1.97$ to 3.42$)$ & 0.001 & $0.32(-2.39$ to 3.02$)$ & 0.01 & $0.40(-2.26$ to 3.06$)$ & 0.02 \\
\hline SEBT posterolateral & $1.03(-0.82$ to 2.87$)$ & 0.0001 & $0.54(-1.21$ to 2.29$)$ & 0.04 & $0.24(-1.49$ to 1.96$)$ & 0.07 \\
\hline SEBT posteromedial & $1.08(-1.10$ to 3.25$)$ & 0.0001 & 0.71 (-1.61 to 3.01$)$ & 0.001 & 0.36 (-1.98 to 2.61$)$ & 0.08 \\
\hline
\end{tabular}

SEBT, Star Excursion Balance Test.

dynamic core stability measures than an identical home-based programme. The home-based programme's effect was restricted to greater static core muscle endurance compared to the control group and may have been influenced by the similarity between some of the less complex exercises and the specific tests used, for example side-bridge endurance. This finding may have therapeutic relevance as greater isometric core muscle endurance in the three static tests selected for the current study is associated with better spine stability during most activities. ${ }^{14}$

\section{Supervised intervention provides superior outcome}

In general, supervised exercise interventions are more effective than home-based interventions. ${ }^{11}{ }^{31-33}$ Bronfort et $a l^{12}$ also showed greater improvement in trunk muscle endurance in people undertaking supervised classes compared to those doing a different exercise programme at home. Based on the outcomes of the current trial, it is likely that the difference in method of programme delivery used by Bronfort et $a l^{12}$ may largely explain the superior outcomes in the supervised group, independent of the different types of exercises being used. Our use of the same exercise programme for both the home-based and supervised groups in the present study clearly demonstrates that the delivery method of the programme has a significant influence on the outcomes of core-strengthening programmes.

For the dynamic measures of core stability the supervised programme again produced significantly better results than the home-based programme. Furthermore the home-based programme failed to produce any significant improvement in the Sahrmann test and the posterolateral and posteromedial directions of the SEBT compared to the control condition. Although there was a significant improvement in the anterior direction of the SEBT by those in the home-based programme compared to the control group, the improvement in the supervised group was significantly greater.

Table 4 Correlations between compliance and measurement outcomes at follow-up testing for the supervised and home-based groups

\begin{tabular}{llc}
\hline Core stability test & Supervised group $(r)$ & Home-based group $(r)$ \\
\hline Sahrmann & $0.63^{* *}$ & -0.13 \\
Side-bridge endurance & 0.33 & 0.23 \\
Flexor endurance & $0.57^{* *}$ & $0.49^{*}$ \\
Sorensen & $0.54^{*}$ & 0.26 \\
SEBT anterior & $0.44^{*}$ & 0.20 \\
SEBT posterolateral & $0.59^{* *}$ & 0.18 \\
SEBT posteromedial & $0.61^{* *}$ & 0.24 \\
\hline
\end{tabular}

*Significant at $\mathrm{p}=0.05 ;$ * Significant at $\mathrm{p}=0.01$.

SEBT, Star Excursion Balance Test.
The Sahrmann test assesses spinal stability with and without movement of the lumbopelvic complex, ${ }^{16}$ whereas the SEBT measures dynamic stability with poorer performance associated with mechanical or sensorimotor deficits. ${ }^{34}$ Our findings suggest that a home-based unsupervised core-strengthening programme may be less effective for neuromuscular retraining and produces less improvement in core stability during dynamic tasks than a supervised programme. Previous research demonstrated improved activation of deep core stabilising muscles during trunk flexion activities in association with verbal and tactile cues. ${ }^{13}$ Instruction on stabilisation also altered the motor control strategy of trunk musculature and produced increased lumbar spine control during upper and lower body movements. ${ }^{35}$ Although participants in the home-based group in our trial received initial verbal instruction, demonstration and written instruction on performance of all exercises, our results suggest this was not sufficient to achieve significant change in neuromuscular control strategies to improve dynamic core stability. This may be related to a lack of understanding of the progression of exercises demonstrated in the initial instruction session potentially resulting in reduced compliance or participants performing more demanding tasks incorrectly.

\section{Compliance}

Self-reported compliance in the home-based programme was higher than recorded attendance for the supervised group. However, correlations between compliance and pre-test and post-test change in core stability measures demonstrated stronger associations in the supervised group. This may have been due to more effective training in the supervised programme, but may also have been influenced by over-reporting of compliance in the home-based group. Although increased attendance at the supervised classes was associated with improved performance across all tests, the strongest relationships occurred with the

Table 5 Test-retest reliability

\begin{tabular}{lrcccc}
\hline & $\begin{array}{l}\text { Test } \\
\text { mean }\end{array}$ & $\begin{array}{l}\text { Retest } \\
\text { mean }\end{array}$ & ICC & $\begin{array}{l}\text { 95\% Cl } \\
\text { for ICC }\end{array}$ & $\begin{array}{l}\text { Paired } \\
\text { t test } \\
\text { p value }\end{array}$ \\
\hline Sahrmann (level) & 0.50 & 0.57 & 0.87 & 0.74 to 0.96 & 0.19 \\
Side-bridge endurance (s) & 13.93 & 15.33 & 0.82 & 0.62 to 0.93 & 0.85 \\
Flexor endurance (s) & 33.54 & 30.72 & 0.91 & 0.75 to 0.97 & 0.17 \\
Sorensen (s) & 17.22 & 16.69 & 0.80 & 0.60 to 0.92 & 0.61 \\
SEBT anterior (cm) & 79.06 & 78.43 & 0.83 & 0.72 to 0.94 & 0.71 \\
SEBT posterolateral (cm) & 70.73 & 71.67 & 0.86 & 0.71 to 0.96 & 0.31 \\
SEBT Posteromedial (cm) & 74.08 & 75.24 & 0.85 & 0.79 to 0.98 & 0.42 \\
\hline n=15. & & & & &
\end{tabular}


Sahrmann test, the posteromedial and posterolateral SEBT. These results suggest increased adherence to supervised training programmes may produce better outcomes for more demanding dynamic tasks that not only require increases in core muscle strength, but also high levels of neuromuscular control. The strong association between the compliance and both the flexor endurance and the Sorensen tests suggests maintaining the training programme as close to two sessions per week as possible can produce better trunk flexor and extensor endurance.

In the home-based programme the strength of association between self-reported compliance and change in measured outcomes was generally low. This may have been due to a smaller effect on outcome measures of the exercise programme conducted in a non-supervised environment or due to overreporting of compliance. The significant positive correlation for flexor endurance with the number of sessions performed, in conjunction with the significant improvement seen for this outcome postintervention, suggests participants may have performed exercises targeting the anterior abdominal muscles more frequently or with better technique. High reported compliance with the intervention and small changes in measured outcomes may also have confounded other potential associations.

\section{Outcome measure reliability}

Test-retest reliability was performed for all outcome measures in this trial. This was not our primary aim and the assessments used have been demonstrated previously to have adequate reliability. $^{321}{ }^{35-38}$ However, the subjective nature of the end point of several of the tests, where the researcher was required to specify the time point at which a participant 'failed' based on observation, meant establishing reliability of assessments specifically for this trial was warranted. The ICCs ranging from 0.80 to 0.91 indicated excellent test-retest reliability and were consistent with existing literature. ${ }^{3} 21{ }^{35-38}$ No change in values between test sessions is a further indicator of good test-retest reliability. This indicates that improvements in outcome measures for the home-based and supervised training programmes represent true changes as a result of the intervention.

\section{Limitations}

Our findings support the use of a supervised programme over a home-based programme for improving static core muscle endurance and dynamic core stability. This study targeted participants with poor dynamic core stability, with trial inclusion requiring a Sahrmann test performance of level one or less. Participants with current pathology that may be attributable to poor core stability, such as low back pain, were excluded. Therefore, although it is evident from this trial that participants with poor dynamic core stability demonstrate an improved response to core training in a supervised environment, it is not known if this translates to exercise intervention for pathologies, such as low back pain, where the initial level of dynamic core stability may be more variable. Existing evidence has demonstrated altered function of deep core stabilising muscles, such as transversus abdominis, during activity in people with low back pain. ${ }^{3}$ This suggests that improving dynamic core stability is an essential component of rehabilitation for low back pain. The current trial findings indicate that a supervised core strengthening programme may be advisable, but further investigation on specific cohorts, including those with low back pain, ${ }^{39}$ needs to be undertaken to determine if supervised programmes also provide the best results in those cohorts.

A further limitation of this study was the nature of the core strengthening programme delivered. The same programme was given to both the supervised and home-based groups to isolate the effect of method of delivery on core muscle endurance and dynamic stability. However, due to the reliance on the participant to perform the exercises in an ongoing manner following initial instruction, a home-based programme may require a different approach. Home-based programmes may benefit from including specific exercises more congruent with being performed without instruction to maximise outcomes. Investigation of effectiveness of specific types of programmes delivered in a home-based environment needs to be undertaken to develop a more effective method for core strengthening to be undertaken without supervision. In addition the outcomes of supervised programmes may be influenced by the method of instruction. While it was not the purpose of this study to investigate the role of the instructor this is also an important area for further investigation.

\section{CONCLUSION}

The results of this study support the use of a supervised core-strengthening programme over a home-based programme to maximise improvement in static core muscle endurance and dynamic core stability in a healthy population with low core stability. Further research is recommended to assess if a supervised core-strengthening programme will also provide a greater therapeutic benefit than a similar home-based programme for pathologies associated with reduced core stability, such as low back pain.

\section{What are the new findings}

- Supervised core-strengthening programmes result in better static and dynamic core stability outcomes than home-based programmes.

- Home-based core strengthening programmes improve static core endurance, but not dynamic core stability.

- Training compliance in the supervised programme was positively correlated with most core stability outcomes.

\section{How might it impact on clinical practice in the near} future

- Supervised core strengthening-programmes may provide greater treatment benefits for musculoskeletal pathologies associated with poor core stability than home-based programmes.

- Home-based core-strengthening programmes may be prescribed to improve static core stability, but are not likely to improve dynamic core stability.

- Supervised core-strengthening programmes are needed to improve core stability for more demanding dynamic tasks.

Contributors $\mathrm{VHC}$ and XAKJdJ planned the randomised controlled trial. VHC, XAKJdJ and BMT conducted the trial. All authors contributed to the reporting of the trial.

Funding This research was supported by funding from the Priority Research Centre for Physical Activity and Nutrition, The University of Newcastle, Australia.

\section{Competing interests None.}

Ethics approval Human Research Ethics Committee of the University of Newcastle Australia (protocol \# H-2012-0013).

Provenance and peer review Not commissioned; externally peer reviewed.

Data sharing statement The corresponding author can be contacted for access to the data presented in this manuscript. 


\section{REFERENCES}

1 Kibler WB, Press J, Sciascia A. The role of core stability in athletic function. Sports Med 2006;36:189-98.

2 Ebenbichler GR, Oddsson LI, Kollmitzer J, et al. Sensory-motor control of the lower back: implications for rehabilitation. Med Sci Sports Exerc 2001;33:1889-98.

3 Hodges PW, Richardson CA. Delayed postural contraction of transversus abdominis in low back pain associated with movement of the lower limb. J Spinal Disord 1998;11:46-56.

4 Ireland ML, Willson JD, Ballantyne BT, et al. Hip strength in females with and without patellofemoral pain. J Orthop Sports Phys Ther 2003;33:671-6.

5 Leetun DT, Ireland ML, Willson JD, et al. Core stability measures as risk factors for lower extremity injury in athletes. Med Sci Sports Exerc 2004;36:926-34.

6 Chuter VH, Janse de Jonge XA. Proximal and distal contributions to lower extremity injury: a review of the literature. Gait Posture 2012;36:7-15.

7 Standaert CJ, Weinstein SM, Rumpeltes J. Evidence-informed management of chronic low back pain with lumbar stabilization exercises. Spine J 2008;8:114-20.

8 Barr KP, Griggs M, Cadby T. Lumbar stabilization: a review of core concepts and current literature, Part 2. Am J Phys Med Rehabil 2007;86:72-80.

9 May S, Johnson R. Stabilisation exercises for low back pain: a systematic review. Physiotherapy 2008;94:179-89.

10 Haladay DE, Miller SJ, Challis J, et al. Quality of systematic reviews on specific spinal stabilization exercise for chronic low back pain. J Orthop Sports Phys Ther 2013;43:242-50.

11 Bendermacher BL, Willigendael EM, Teijink JA, et al. Supervised exercise therapy versus non-supervised exercise therapy for intermittent claudication. Cochrane Database Syst Rev 2006;19:CD005263.

12 Bronfort G, Maiers MJ, Evans RL, et al. Supervised exercise, spinal manipulation, and home exercise for chronic low back pain: a randomized clinical trial. Spine J 2011;11:585-98.

13 Karst GM, Willett GM. Effects of specific exercise instructions on abdominal muscle activity during trunk curl exercises. J Orthop Sports Phys Ther 2004;34:4-12.

14 McGill S. Low back disorders: evidence based prevention and rehabilitation. Champaign, IL: Human Kinetics, 2007.

15 Norris CM. Functional load abdominal training: part 1. J Bodyw Mov Ther 1999:3:150-8.

16 Faries MD, Greenwood M. Core training: stabilizing the confusion. Strength Cond J 2007;29:10-25.

17 Ekstrom RA, Donatelli RA, Carp KC. Electromyographic analysis of core trunk, hip, and thigh muscles during 9 rehabilitation exercises. J Orthop Sports Phys Ther 2007;37:754-62

18 Lust KR, Sandrey MA, Bulger SM, et al. The effects of 6-week training programs on throwing accuracy, proprioception, and core endurance in baseball. J Sport Rehabil 2009;18:407-26.

19 McGill S. Low back stability: from formal description to issues for performance and rehabilitation. Exerc Sport Sci Rev 2001;29:26-31.

20 Samson KM, Sandrey MA, Hetrick A. A core stabilization training program for tennis athletes. Athletic Therapy Today 2007;12:41-6.
21 Stanton R, Reaburn PR, Humphries B. The effect of short-term Swiss ball training on core stability and running economy. J Strength Cond Res 2004; 18:522-8.

22 Drysdale $\mathrm{CL}$, Earl JE, Hertel J. Surface electromyographic activity of the abdominal muscles during pelvic-tilt and abdominal-hollowing exercises. J Ath Train 2004;39:32-6.

23 Demoulin C, Vanderthommen M, Duysens C, et al. Spinal muscle evaluation using the Sorensen test: a critical appraisal of the literature. Joint Bone Spine 2006;73:43-50

24 Kahle NL, Gribble PA. Core stability training in dynamic balance testing among young, healthy adults. Athletic Training Sports Health Care 2009;1:65-73.

25 Gribble PA, Hertel J. Considerations for normalizing measures of the star excursion balance test. Meas Phys Educ Exerc Sci 2003;7:89-100.

26 Robinson RH, Gribble PA. Support for a reduction in the number of trials needed for the star excursion balance test. Arch Phys Med Rehabil 2008;89:364-70.

27 Hertel J, Braham RA, Hale SA, et al. Simplifying the star excursion balance test: analyses of subjects with and without chronic ankle instability. J Orthop Sports Phys Ther 2006;36:131-7.

28 Munro AG, Herrington LC. Between-session reliability of the star excursion balance test. Phys Ther Sport 2010;11:128-32.

29 Cohen J. Statistical power analysis for the behavioral sciences. Hillsdale, NJ: Erlbaum Associates, 1988.

30 Fleiss JL. Reliability of measurement. New York: John Wiley \& Sons, 1986.

31 Nicolaï SP, Kruidenier LM, Leffers $P$, et al. Supervised exercise versus non-supervised exercise for reducing weight in obese adults. J Sports Med Phys Fitness 2009;49:85-90.

32 Olney SJ, Nymark J, Brouwer B, et al. A randomized controlled trial of supervised versus unsupervised exercise programs for ambulatory stroke survivors. Stroke 2006;37:476-81.

33 Evans R, Bronfort G, Schulz C, et al. Supervised exercise with and without spinal manipulation performs similarly and better than home exercise for chronic neck pain: a randomized controlled trial. Spine 2012;37:903-14

34 Hoch MC, Staton GS, McKeon PO. Dorsiflexion range of motion significantly influences dynamic balance. J Sci Med Sport 2011;14:90-2.

35 Webber SC, Kriellaars DJ. The effect of stabilization instruction on lumbar acceleration. Clin Biomech 2004;19:777-83.

36 Plisky PJ, Rauh MJ, Kaminski TW, et al. Star Excursion Balance Test as a predictor of lower extremity injury in high school basketball players. J Orthop Sports Phys Ther 2006;36:911-19.

37 Jørgensen K, Nicolaisen T. Two methods for determining trunk extensor endurance. A comparative study. Eur J Appl Physiol Occup Physiol 1986;55:639-44.

38 McGill SM, Childs A, Liebenson C. Endurance times for low back stabilization exercises: clinical targets for testing and training from a normal database. Arch Phys Med Rehabil 1999;80:941-4.

39 Morton S, Barton CJ, Rice S, et al. Risk factors and successful interventions for cricket-related low back pain: a systematic review. Br J Sports Med 2014;48:685-91. 